\title{
Prefrontal Cortex
}

National Cancer Institute

\section{Source}

National Cancer Institute. Prefrontal Cortex. NCI Thesaurus. Code C154779.

The grey matter on the medial, lateral, and orbital surfaces of the anterior part of the frontal cortex, which play a role in complex cog nitive control, emotion, and social behavior. 